\title{
Exploring everyday mobility in a living lab based on economic interventions
}

\author{
Martin Sjöman ${ }^{1 *}\left(\mathbb{D}\right.$, Tina Ringenson ${ }^{2}$ and Anna Kramers ${ }^{2}$
}

\begin{abstract}
New mobility solutions, such as Mobility as a Service, have been suggested to have the potential to reduce car ownership and be part of a transition towards a more sustainable transportation system. However, research suggests that governance measures such as taxation and policies will be needed to ensure sustainability aspects. This paper explores everyday mobility by use of interventions in people's everyday lives. The focus is on identifying underlying factors that may motivate or hinder changes that are positive from a sustainability perspective. This is then put in the perspective of new mobility services and policy making. Our findings support the view that privately owned cars are hard to replace with new mobility services that contribute to sustainability and are not based on individual cars. Economic interventions for increased sustainability will likely have limited effects, since the alternatives do not offer what car owners value most. Also, limited understanding of the car's full costs may make the new services appear comparatively more expensive. Furthermore, urban planning to reduce the need for travel, and the capacity of the physical public transport infrastructure will continue to be important. Long vacation trips and "medium sized flows" are identified as opportunities for further research and for new solutions to support sustainable mobility transitions.
\end{abstract}

Keywords: Mobility as a service, Smart mobility, Environment, Sustainability, Travel, TravelVU

\section{Introduction}

There is a broad consensus among researchers, industry and governmental actors that digitalization and other technological advances can enable a changed transport system, and that this transition has already begun. The changed transport system is often referred to as "smart mobility" (see e.g. [12, 17, 41]). Mobility as a Service (MaaS) is often mentioned as an important part of future smart mobility. MaaS can be described as a service concept using a digital interface to offer a mix of mobility services and bring different types of transport options together, thereby enabling a seamless journey [40]. Often, this concept includes some type of mobility subscription plans for various transport modes [31, 39]. It has been suggested that these services offer alternatives to car ownership. Smart mobility proponents promise opportunities to create large economic benefits, while reducing the congestion and pollution problems associated with the private

\footnotetext{
* Correspondence: martsjo@kth.se

${ }^{1}$ Department of Product \& Service Design, KTH Royal Institute of Technology, Brinellvägen 83, SE-100 44 Stockholm, Sweden

Full list of author information is available at the end of the article
}

car. A recent study by Nalmpantis et al. [40] evaluated new ideas for more attractive public transport with respect to utility, feasibility and innovativeness, and found Mobility as a Service to be the most promising such new idea from a perspective combining those factors. However, as argued by e.g. [12, 43] a smart mobility transition may require thoughtful and well-informed governance if it is to support a sustainable transport transition and produce the desired results for society. Without regulation, digitalized mobility, including MaaS, will likely lead to a new hypermobile culture still based on individual vehicles, and thus increase congestion and pollution problems [12].

Replacing individual motorized vehicles with shared modes of travel (especially Public Transport), bicycling and walking, is important to reduce greenhouse gas emissions. However, it is a difficult task to create public transport services that are as quick and comfortable as on-demand door-to-door services built on individual vehicles. Due to its promise of seamlessness and convenience, MaaS has been seen as a promising way to replace the private car, but development and uptake have been slow. Furthermore, successful new mobility 
services such as Uber are car-based, and mainly replace walking, bicycling and public transport $[10,18]$. There are also a number of specific travel needs where it is hard for the proposed new mobility services to compete with the private car, mostly due to individual destinations out of reach of public transport. Gärling and Schuitema [21] suggest that coercive measures will be needed for a shift from car-based transportation, but that these need to be complemented with non-coercive measures if they are to be politically feasible. Economic incentives and regulations to support a shift from the car-based society may be politically difficult to impose without satisfactory mobility alternatives. MaaS could potentially play a part in reducing greenhouse gas emissions by supporting a shift away from individual vehicles - hereafter, we refer to MaaS that manages to do this as sustainable MaaS. To design attractive and sustainable MaaS offerings, we need to understand which practical needs and mental images may affect mobility choices and practices. In this study, we specifically aimed to explore motivations and hindrances for an uptake of more sustainable mobility practices that could be enabled by MaaS.

This paper describes the results from the Living Lab "Future playing rules for everyday travel" performed in Stockholm, Sweden, June-November 2018. This Living Lab aimed to explore everyday mobility by use of mixed interventions.

Nine participants were introduced to three different economic incentives, designed to promote more environmentally friendly transportation choices. As this was an explorative study, the aim was not to evaluate the effectiveness of the incentives. Instead, their purpose was to trigger the participants to reflect upon their mobility practices and choices. In this way, the participants' reflections and responses let us explore more complex underlying factors and identify barriers and opportunities to change, answering to Gärling and Schuitema's [21] call to disentangle the reasons why Traffic Demand Management measures may work or not.

Finding pathways for continued research, this study can also be seen as a first iteration in a longer research program, aiming to produce the knowledge needed to guide the development of sustainable MaaS.

\subsection{Summary of existing literature related to the aim of this article}

In the light of traffic-related challenges on both global, regional and local levels, how to break the trend of growing volumes of car traffic has become a major topic of research within several different fields. Different Traffic Demand Management measures have been tested. Jakobsson et al. [30] find that "even substantial economic disincentives are unlikely to lead to any large reduction in private car use". In a review of the field
Gärling and Schuitema [21] conclude that coercive measures such as costs or regulation are nevertheless needed, but are difficult to implement as they must be both acceptable to the public and politically feasible. Furthermore, a more recent review by Arnott et al. [3] finds no evidence for the efficacy of behavioral interventions, aiming to change beliefs or attitudes, or providing economic incentives.

Habit has been described as a powerful predictor of present behaviour [42]. Gärling and Axhausen [20] show how car-use habit can be an important barrier to reducing car use, but in the same special issue Bamberg et al. [5] show that even habitual car users may react positively to interventions to promote public transport, when in a new decision context such as when moving residences.

Graham-Rowe et al. [19] describe such changing contexts as one of few promising exceptions, finding that the evidence for structural interventions to reduce caruse is generally weak, and the effects limited.

In the present study we aim to understand more about which contextual factors and individual understandings may influence the efficacy of efforts to reduce car use and promote alternatives, such as Sustainable MaaS. Also, many studies in this field focus on measures to convert car commuters to use public transport, but the largest opportunities for MaaS to replace the car may be in non-work-related travel. In Stockholm, as in many cities in developed countries, many already commute by public transport but mostly use the car in the spare time. In Stockholm $43 \%$ of commuting trips are made by public transport, but only $23 \%$ of trips made in the leisure time [49]. This study aims to explore reasons behind this.

Lättman et al. [35] question the commonly used "objective" measuring of accessibility and have instead worked to capture perceived accessibility, "the individual perspective of accessibility with a certain travel mode" (p. 501) defined as "how easy it is to live a satisfactory life with the help of the transport system" ([34], p. 36). This perspective does not only take objectively measurable factors such as travel time into account, but also subjective factors such as feelings of security and access to information [35]. Comparison between measurements of accessibility measured objectively and subjectively showed that these often do not correspond [35]. As MaaS proposes to contribute with improved route planning and more seamless travel, it may improve perceived accessibility even when only connecting existing travel modes. Therefore, we aim at examining such individual perceptions of ease of travel.

It has been known for decades that people generally have very limited active knowledge of the full cost of owning and operating private cars. Car owners are known to consciously or unconsciously repress parts of 
the costs (see for example [7]). Many car owners only calculate operational costs, such as fuel, and disregard the car's depreciation in value, which is often the single largest cost of car ownership. A recent study shows that limited understanding of the Total Cost of Ownership (TCO) is a barrier to the uptake of electric cars [24]. In this study only $42 \%$ of potential car-buyers estimated the cost of ownership, and only $8 \%$ included depreciation of value. Other studies indicate that car costs can have an impact on car-driving choices, but that people mostly only calculate with the cost of fuel [6]. In our study, we investigate such potential impacts.

Recent research indicates that the costs of public transport are increasing [15], and that the cost of accommodating to the maximal traffic volumes during rush hours is a significant part of the increase [36]. Many attempts have been made to curb these peaks. For example, in an experiment in Singapore, a large group of people were offered to travel for free if they exited the public transport-system before $7.45 \mathrm{am}$. This resulted in a $5.5 \%$ reduction in travel during peak hours - a rather small shift that could however imply long-term financial savings on infrastructure investments [53]. Tyrinopoulos and Antoniou [50] have also found that crowding is one of the most important factors that may discourage public transport use, which suggests that it might be important to even out the load on public transport. In this study, we aim to understand more about which circumstances make such incentives work or not.

According to [45], positive societal effects of bicycling on e.g. health and environment, are so large that building bicycling lanes is profitable for society. Bicycles take up less space than cars, and bicycling can help reduce pressure on highways and commuter trains alike. However, research shows that comfort factors regarding for example weather, physical effort and perceived safety affect bicycling, both for recreation and for transportation $[44,52]$. To put it simply, despite its advantages bicycling can be perceived by many as inconvenient.

In the Netherlands, Belgium, Italy, and France, there are programs to incentivize bicycling to work by offering bicyclists $0.2-0.25 € /$ travelled kilometre. The results this far have been modest but positive. The Dutch Brabant Region has around 2 million inhabitants, and the B-Riders program is estimated to have made 8500 motorists shift to commuting by bicycle. $([4,13])$. In the UK however, a large survey (stated preference) suggested that payments for cycling to work could be very effective, and that a $£ 2$ daily payment could potentially almost double the level of cycling [51]. In this study, we aim to learn more about how such rewards are experienced, and which factors may influence their effect.

\section{Method}

Living Labs are often described as real-life places for user co-creation [8]. Living Labs, however, come in a host of variations and there are many different definitions. The European Network of Living Labs (Accessed 26 November 2019) highlight the lab as an infrastructure or eco-system for open innovation. This paper describes another type of Living Lab based on design methodology and designed as an explorative study. This design driven or interventionist Living Lab method is being developed at KTH Royal Institute of Technology in Sweden. This type of Living Labs is based on imposing interventions into people's real lives and over time, often for several months. Such interventions could consist of changes designed to substantialize and try out possible futures, such as radically new service propositions. In some cases, the interventions mainly trigger user reflection, thereby uncovering tacit norms or beliefs. In other cases, the interventions may require participants to experiment with changing their habits to adapt to the new situation. In either case, the purpose is not to evaluate or assess the effectiveness of a specific solution, but to explore innovative concepts and possible futures. (For descriptions of other such living labs, see e.g. [25, 27, 47].

In the Living Lab described in this paper the intervention comprised of three different economic incentives connected to mobility, designed to function as a trigger material. Trigger materials or probes are frequently used in design practice to elicit user reflection and responses $[32,38]$. In this case, offering new information and economic incentives triggered the participants to reflect upon their everyday mobility practices. By interviewing the participants and logging their travel patterns over time, we aimed to explore how underlying factors such as mobility needs, societal norms, or cognitive biases may support or hinder more sustainable mobility practices.

The study spanned six months between June and November 2018, as well as a baseline measurement month before the interventions were presented to the participants. Throughout the study, all the participants' trips were logged using the mobile phone app TravelVU, as described in section 2.5 .

\subsection{Recruiting participants}

To be able to get an in-depth understanding of needs, attitudes and mobility practices and still get a broad range of experiences, we wanted a small but relatively heterogeneous group. As the living lab was explorative, the aim was not to enable statistical analysis, but to gain a rich understanding of several different individual perspectives. Participants were randomly recruited outside the main grocery stores in four previously identified neighborhoods in the southern Stockholm region. These neighborhoods had different distances to the city center and different access to public transport, where rail bound modes were seen as most important. The reason 
for recruiting at grocery stores was that that they are visited by most local inhabitants, and commonly reached by car. We had decided that all participants should be car-owners, since society has much to gain if MaaS could replace the private car. After brief phone interviews 20 participants took part in a one-month base measurement of their everyday travel by use of the TravelVU app. After assessment of the travel data, 9 participants were selected. There were slightly more men than women, but the group provides a good variation of mobility related factors such as family situation, housing area, car use and car costs. All the participants expressed their consent to anonymized publication of the data available in this document. The participants are shown in Table 1.

\subsection{Intervention 1: making the costs of car ownership transparent}

Through this intervention we wanted to know more about how the limited understanding of car costs may influence car driving practices and related attitudes towards alternative modes of travel. To explore this, we created a solution to make the full cost of driving visible to the participants.

The total cost of owning and driving a private car was divided into four categories:

1. Fixed costs, such as tax and renting a parking spot

2. Semi-fixed costs, such as insurance and devaluation. These costs are to a large extent based on how new and expensive a car is, but are to some degree affected by mileage.
3. Variable costs, such as fuel, service, and replacing tires and brakes. (Yearly service packages were counted as semi-fixed costs in some cases).

4. Unforeseen costs, such as accidents, repairs or parking fines.

First, the total yearly fixed and semi-fixed costs were estimated for each participants' car. This was done using historical costs from the past year, devaluation was estimated by a consultancy specialised in valuation and cost analysis of cars (www.autovista.se). The variable costs were estimated using the participants' historical costs and a public database on real world gas consumption (www.spritmonitor.de). Unforeseen costs were excluded. See Table 2.

To create a baseline, before the actual interventions were introduced, the participants were asked to log their travelling for a "normal" month (April in this case) with the help of the TravelVU application. The car's total cost was then turned into a cost per kilometre, by dividing it with the number of kilometres the participant usually drives every year, using the baseline from the measurement month as well as protocols from the obligatory yearly car inspection, and the participants' own projections. The total cost per kilometre was shown to the driver via the TravelVU app. A pop-up window appeared at the end of each car trip, showing its cost to the user.

The participants in this study owned relatively old cars, and their costs varied from 2.8 to $7.6 \mathrm{SEK} / \mathrm{km}$ ( $0.23-0.73 € / \mathrm{km})$. Including participants with very new cars could have added other perspectives since they are generally much more expensive to own, when value

Table 1 Participants in the Living Lab

\begin{tabular}{|c|c|c|c|c|}
\hline $\begin{array}{l}\text { Participant Gender, Age } \\
\text { Bracket }\end{array}$ & $\begin{array}{l}\text { Housing } \\
\text { type }\end{array}$ & $\begin{array}{l}\text { Type of area, Public transport } \\
\text { accessibility }\end{array}$ & Family Situation & Normal mode of commuting \\
\hline M1 40 s & Apartment & $\begin{array}{l}\text { Inner city. Very close to rail } \\
\text { bound PT. }\end{array}$ & $\begin{array}{l}\text { Single. Lives with two children } \\
10 \text { and } 12 \text {, every second week }\end{array}$ & Bicycle or public transport \\
\hline $\begin{array}{l}P 2 \\
M, 40 s\end{array}$ & Apartment & $\begin{array}{l}\text { Inner suburb. } 500 \mathrm{~m} \text { to rail } \\
\text { bound PT }\end{array}$ & Single. & Car to work \\
\hline $\begin{array}{l}\text { P3 } \\
M, 40 s\end{array}$ & Apartment & $\begin{array}{l}\text { Outer suburb, } 2 \mathrm{~km} \text { to rail } \\
\text { bound PT }\end{array}$ & $\begin{array}{l}\text { Girlfriend in different city. Two } \\
\text { teenage sons. }\end{array}$ & Car to work \\
\hline $\begin{array}{l}\text { P4 } \\
M, 50 s\end{array}$ & Apartment & $\begin{array}{l}\text { Inner suburb. Very close to rail } \\
\text { bound PT }\end{array}$ & $\begin{array}{l}\text { Girlfriend in another part of the } \\
\text { city, son (16) living at home, one } \\
\text { grown up child moved out }\end{array}$ & Walks to work \\
\hline $\begin{array}{l}\text { P5 } \\
M, 20 s\end{array}$ & $\begin{array}{l}\text { Detached } \\
\text { house }\end{array}$ & $\begin{array}{l}\text { Inner suburb. } 1 \mathrm{~km} \text { to rail } \\
\text { bound PT }\end{array}$ & $\begin{array}{l}\text { Lives with parents. Can borrow } \\
\text { the family car. }\end{array}$ & $\begin{array}{l}\text { Walk/bus + commuter train + walk/bus. } \\
\text { Or bike, } 12 \mathrm{~km} \text {. }\end{array}$ \\
\hline $\begin{array}{l}\text { P6 } \\
\text { M, 50s }\end{array}$ & & & $\begin{array}{l}\text { Lives with wife and two sons } 19 \\
\text { and } 23 \text { (P5) }\end{array}$ & Walk/bus + commuter train + walk/bus \\
\hline M7 40 s & $\begin{array}{l}\text { Detached } \\
\text { house }\end{array}$ & $\begin{array}{l}\text { Inner suburb. } 2 \mathrm{~km} \text { to rail } \\
\text { bound PT }\end{array}$ & $\begin{array}{l}\text { Married to P8. Pre-school age } \\
\text { daughter. }\end{array}$ & Bicycle to work. \\
\hline $\begin{array}{l}\text { P8 } \\
F, 40 s\end{array}$ & & & $\begin{array}{l}\text { Married to P7. Pre-school age } \\
\text { daughter. }\end{array}$ & $\begin{array}{l}\text { Walks + public transport to work and } \\
\text { to studies. }\end{array}$ \\
\hline $\begin{array}{l}P 9 \\
F, 50 s\end{array}$ & Apartment & $\begin{array}{l}\text { Inner suburb. } 1,5 \mathrm{~km} \text { to rail } \\
\text { bound PT }\end{array}$ & $\begin{array}{l}\text { Single, grown up children have } \\
\text { moved out }\end{array}$ & Car to work \\
\hline
\end{tabular}


Table 2 Cost of ownership of cars

\begin{tabular}{|c|c|c|c|c|c|}
\hline Participant & Car model & Production year & Est. fixed \& semi-fixed costs/km (SEK/km) & Est. variable costs/km (SEK/km) & Est. km driving per yea \\
\hline $\mathrm{P} 1$ & Skoda Roomster & 2007 & 2,0 & 1,6 & 8500 \\
\hline P2 & Audi A5 & 2011 & 5,3 & 2,3 & 6600 \\
\hline P3 & Audi A4 & 2004 & 0,7 & 2,0 & 34,000 \\
\hline P4 & Volvo V60 & 2012 & 1,7 & 1,4 & 14,400 \\
\hline P5, P6 & Volvo V70 & 2008 & 1,4 & 2,1 & 11,200 \\
\hline P7, P8 & Citroën Tourer & 2009 & 2,3 & 2,4 & 8000 \\
\hline P9 & WW Golf & 2000 & 1,3 & 1,5 & 10,400 \\
\hline
\end{tabular}

deprecation is included in the cost of the car. In financial models, the depreciation-rate is commonly approximated as loosing $50 \%$ of the car's value in the first three years [26]. Information on the participants' cars can be found in Table 2.

Monthly driving was measured using the TravelVU app, and checked against the car's odometer twice during the living lab. The household was then to pay only the kilometre cost. If the participant drove as usual, the cost would be the same as usual. If they drove less, the cost for that month would be lower, as in this case the research program would cover the remaining fixed and semi-fixed costs. If the participant drove more than usual, the cost would be higher, but in this event the participant was only informed of the higher cost. The research project saw no way to actually demand that participants pay money to the research project. A calculation of the monthly cost was sent to the participants at the end of every month, an in the case of savings, the participants received a bank payment.

As the living lab focused on everyday travel, the participants were asked to exclude planned longer vacation trips by car from the logging of travel patterns, but these trips were still included when calculating the cost of driving.

\subsection{Intervention 2: cheaper public transport during off- peak hours}

For public transport, we wanted to explore the problem of limited capacity during the rush hour and whether time-differentiated pricing could be included in a MaaS system as a step towards solving that problem. We also aim to explore why public transport takes such a small part of leisure trips in a city such as Stockholm, where many commute by public transport.

The public transport system in Stockholm offers two main types of tickets: A monthly travel card with unlimited travel for a fixed price, or a prepaid card for purchasing single trips. The participants were offered monthly travel cards for half the original price - but during peak hours they had to pay an additional 20 SEK ( $2 €)$ per ride, up to the original monthly card price.
When paying per trip, participants simply got a $50 \%$ rebate when travelling off-peak. Travel data from SL, Stockholm Public Transport estimates the peak hours of the Stockholm public transport system to be 7.30-8.30 am and from 16.30-17.30 pm, Monday-Friday [48]. Additionally, since Stockholm's public transport system only registers the time of boarding, people are actually in transit longer. Therefore, we added $15 \mathrm{~min}$ to the peak hour time span, and defined travel during rush hour as travel boarded within a 75-min period from 7.15-8.30 am, and $16.15-17.30 \mathrm{pm}$.

\subsection{Intervention 3: economic rewards for bicycling}

For bicycling, we wanted to understand reasons for and against bicycling, and attitudes towards incentives in this area. The participants were given a reward of $1 \mathrm{SEK} / \mathrm{km}$ $(\sim 0.1 € / \mathrm{km})$ for all bicycling, with distances as measured in the travel monitoring app and reported by the participants. The reward was however limited to a "ceiling" of 400 SEK/month $(\sim 40 €)$, and limited to any travel to a specified destination, not including bicycling for recreation or exercise.

\subsection{Data capture}

The economic incentives were used to trigger experimentation and reflection, and thereby explore which factors affect the participant's propensity to change their travel practices. In an iterative process, interview findings were analysed to extract new questions and preliminary themes that were then further investigated in the next round of interviews. Also, in the later interviews, data from the travel logs was presented to the participants as trigger material, to make the participants reflect upon their practices and understandings. This included discussing changes since the last month's travel, overviewing their own trips on a map, and discussing scenarios based on calculated travel costs. In some cases, unanticipated findings required the researchers' reading up on new research areas.

Two types of data were collected:

First, data from participant interviews and notes from conversations. In-depth interviews were held before, 
after, and in the middle of the living lab. Also, two short phone interviews were made during recruitment and six weeks into the span of the living lab. The interviews were semi-structured, and the questions concerned the participants' travel practices, as well as their needs, attitudes and perceptions, sometimes using hypothetical scenarios. The interview guides were the same for all participants, except in cases when some questions were not relevant due to differences in family situation etc. This data set also included other qualitative inputs from the participants, such as comments made during administrative contacts.

Second, Travel logs from the mobile phone app TravelVU. Quantitative data was collected from a detailed logging of individual travel, using the GPS-tracker app TravelVU, during the whole length of the study. The app includes a visual user interface with colours and symbols that allowed both the participants and the researchers a clear visual overview of the travel (see Fig. 1 for a screenshot; the screenshot includes Swedish text because the app is in Swedish).

The app attempts to identify and separate 16 different modes of travel, and the user is also requested to categorize or manually name the places/activities visited, see Table 3. The app also records switching trains or buses, as well as time spent parking or waiting.

Since logging was automatic, few if any trips were missed altogether, and the distances travelled are

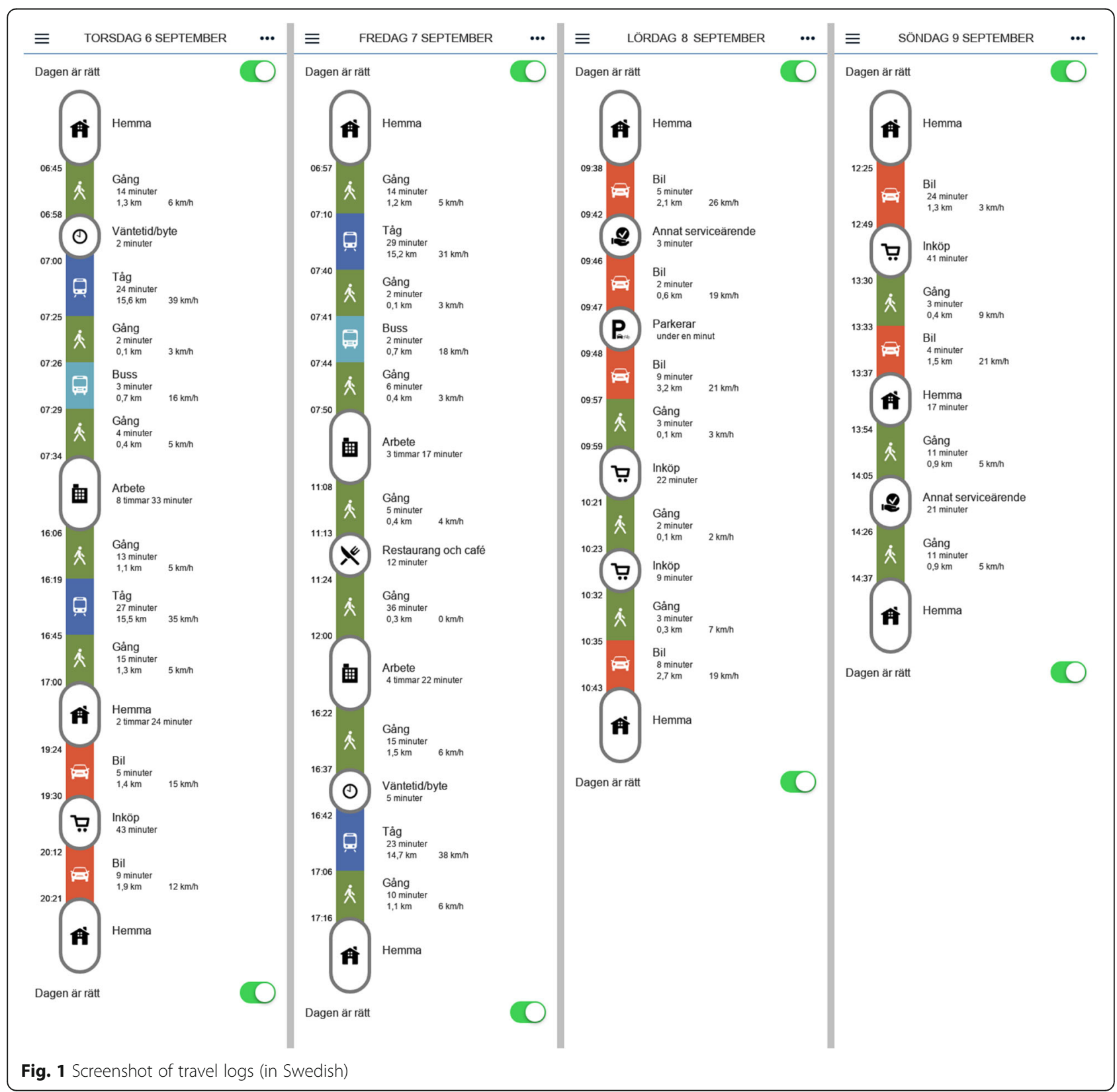


Table 3 Logged travel modes and default categories of activities in TravelVU

\begin{tabular}{ll}
\hline Travel modes & Activities/destinations \\
\hline Walk & Wait/transfer \\
Exercise and recreation & Parking \\
Bicycle & Home \\
Electric Bicycle & Temporary overnight stay \\
Bus & Work \\
Train & School/Education \\
Car & Business \\
Car, as passenger & Drop-off/pick-up \\
Tram & Shopping \\
Metro & Healthcare \\
Moped & Other service errand \\
Motorcycle & Visit friends and relatives \\
Ferry/boat & Sports/outdoor activities \\
Airplane & Restaurants/café \\
Community transport & Hobby \\
Taxi & Entertainment and culture \\
Other mode (type in) & Holiday \\
& Other activity (type in) \\
\hline
\end{tabular}

measured with a relatively high degree of accuracy. Identifying the correct travel modes and activities relies on the participant's manual inputs and corrections, but as all data was carefully reviewed by the researchers, many mistakes and errors could be corrected. On a few occasions, a few days' data was lost due to technical problems or user errors. In all for around $1 \%$ of the days, data was incomplete or lost. When possible, lost data was manually replaced by estimates. For one participant (P9), however, two full months of data was lost due to technical problems with the app, and this data was not replaced. For a more detailed description and analysis of the TravelVU app as a travel logging method, see for example Eriksson et al. [14].

\subsection{Analysis}

The explorative Living Lab method used here does not generate data that is suitable for deductive analysis, or to extract largely applicable patters of human behaviour, and other methods were needed to analyse the rich data.

For the analysis, notes from and transcriptions of the interviews were the main source of data. Comments and similar that had come up during other conversations and meetings with the participants were also added. The themes were also discussed in relation to the quantitative data collected. We analysed the material using post its, following design practice, and going from a large number of "first order categories" as they are described from the participants perspective, gradually clustering them to develop "second order themes", inspired by the Gioia Methodology [23]. In our case, the first order themes were more or less groups of direct quotes from the interviews, such as "one does not want to plan ahead" or "I don't want to know [how much the car costs]!" These were then clustered and sorted into more overarching second order themes, sometimes corresponding to the interview questions and sometimes being more unexpected or emerging themes, such as reasons for car ownership and understandings of the true cost of the car. The Gioia Methodology then describes distilling the themes further into "aggregate dimensions", and in a similar way, our second order themes were discussed within the research team to form different ways to reason, finding conflicts, linkages and other points of interest, as described in the discussion section.

\section{Results}

The following sections describe the results from the interviews with the participants and selected results from the quantitative logging of trips. As described earlier, the calculations based on the travel logs were also used as trigger material for the interviews. Car ownership and car use have been given more attention, since car use has the most negative consequences for the environment.

\subsection{The car}

\subsubsection{Reasons for car ownership and car driving}

Reasons for owning and going by car were often described by the participants as it being comfortable, wanting freedom and allowing for spontaneity, or just "laziness". A married couple mentioned that most of their neighbours owned two cars, and that just having one car was already diverging from the local norm. Although some trips could be carried out by other modes, they were done by car simply out of habit and convenience, because the participants owned one and it was readily available. Explicit reasons for going by car were often saving time in comparison with other transport options, the need to transport groceries, other heavy purchases, or luggage. Not having to plan beforehand often came up in questions about both owning and using the car, whether the planning concerned planning how to make the trip itself, at what time to make it, or possible stops along the way.

Among explicit reasons given for not going by car, the most common and most strongly expressed by the participants were avoiding congestion and parking difficulties. Other reasons mentioned were toll fees and environmental concerns. Additionally, some of the participants said that they might not have used a car if they lived in the city or closer to a subway station, or just in an apartment, since a house and garden requires maintenance and therefore many transports. 


\subsubsection{Needs and destinations that require $a$ car}

A commonly mentioned problem was limited accessibility by public transport to some locations. Most participants identified large shopping centres and recreational sites such as forests or beaches as places that were commonly visited by both themselves and their neighbours, and also difficult to reach by public transport. The participants also had more individual travel needs such as visiting friends or family in other areas of the city, getting to their boat or country house, or to their own or child(ren)'s activities. Many participants also used the car for long vacation trips, such as visiting friends or relatives in other parts of the country or skiing in the mountains. These longer trips were mostly made by car. Reasons were described as "already having [the car]", for the comfort of just "putting all the stuff in the car and go", or to be able to move around once you get there, especially for shopping.

\subsubsection{Measured amount of car-driving}

When creating estimations of the yearly car driving, data from the baseline measurement month was compared with historical odometer readings from yearly car-inspection protocols. The odometer readings in most cases did not cover a full year, but the comparison still clearly showed that the baseline month in most cases was nowhere near 1/ 12 of the participants' normal yearly driving. In 8 out of 9 cases April's logged driving was less or much less than the historical mean value for a month. In one case, it was a quarter of the calculated average, even though the participant believed it was a "normal month regarding driving". It was clear that the cars were used much more than the

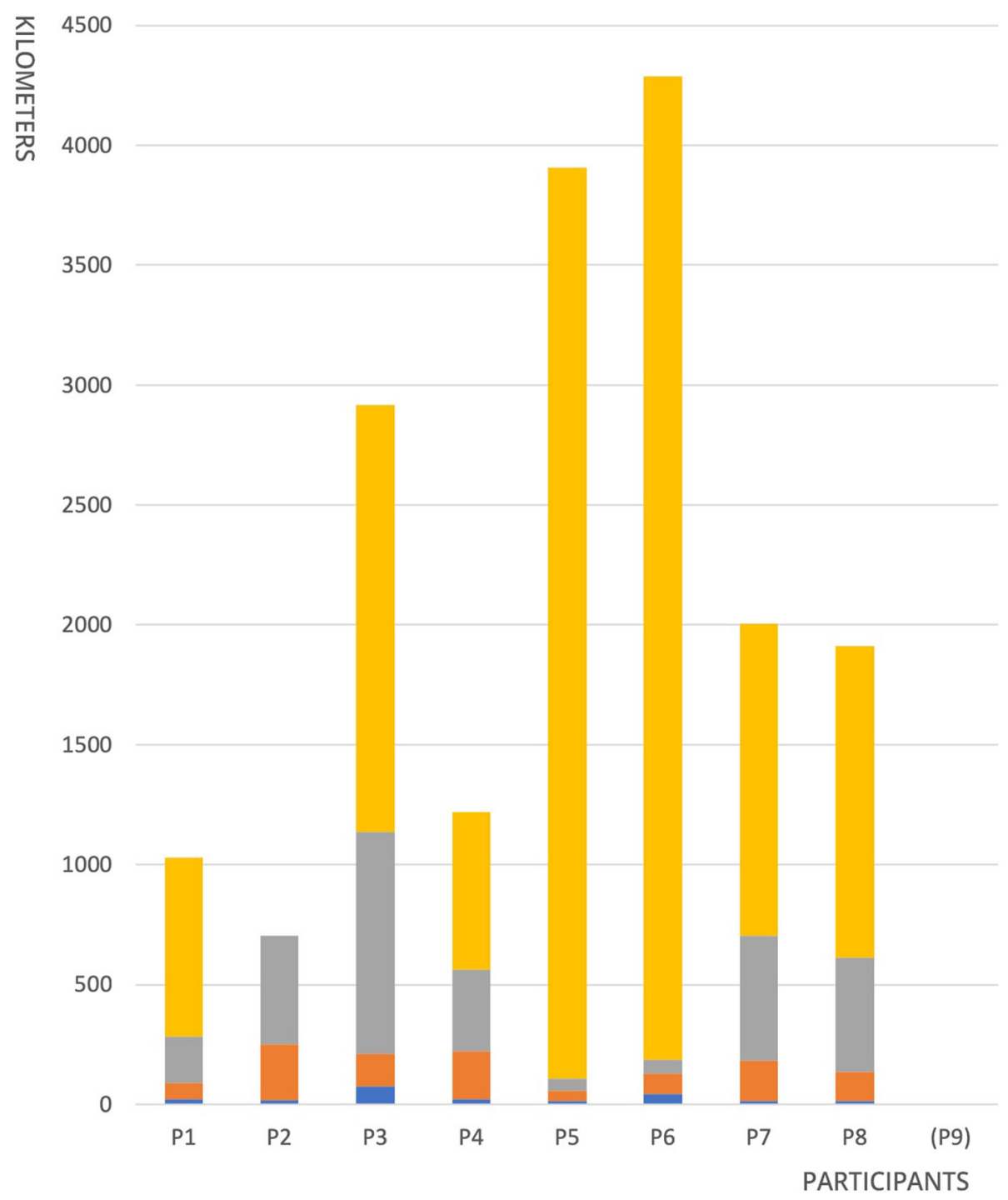

Fig. 2 Kilometre by car in July 


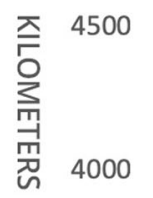

3500

3000

2500

2000

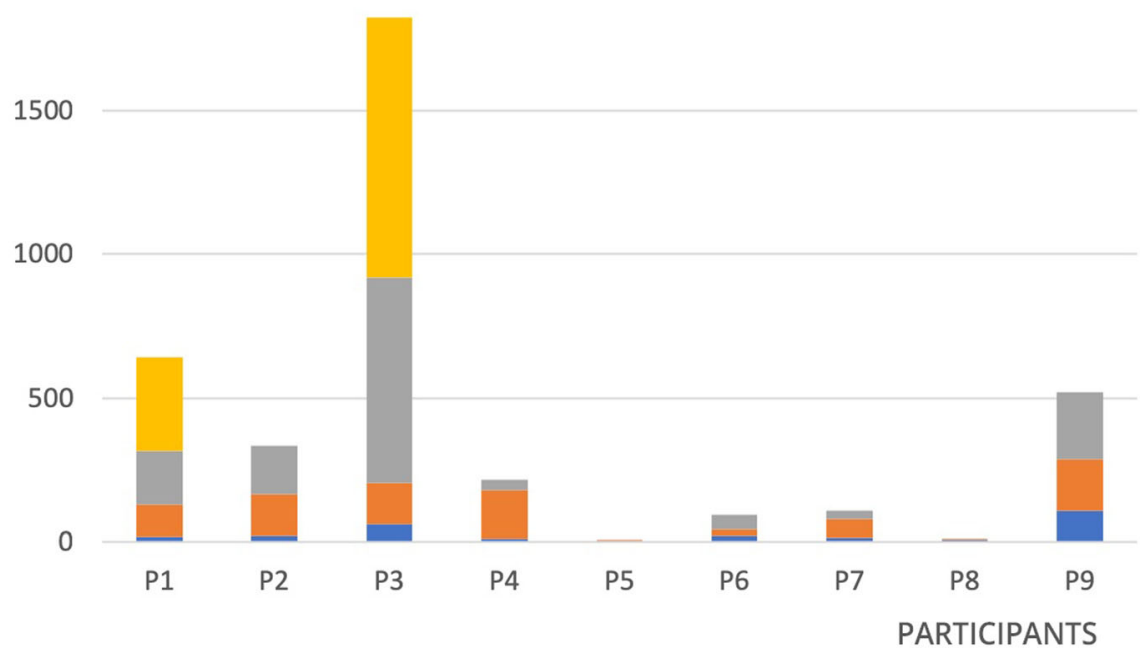

Fig. 3 Kilometre by car in November

baseline measurement indicated. The main reason turned out to be that long vacation trips stood for an unexpectedly large part of the yearly driving, and were mostly carried out during the summer vacation in July. In one case, a few long vacation trips during the summer alone accounted for more than half the yearly driving, and for two other participants more than a third. In other cases, the many visits to the country house were also a significant portion of the yearly driving. The study ended in November, which was also the month with the least driving. See Figs. 2 and 3. Please note that for P9, there is no data for July.

Even when excluding the long vacation trips, car-travel still varied with the seasons. Many of the participants mentioned garden work and maintaining the boat or the house as reasons for more car travel during the warmer months of the year. When mapping the number of car trips for the same two months, we can see that the participants also made fewer trips by car in November (see Figs. 4 and 5). When asked about it, the participants stated that they simply did less things in their spare time in the darker months of the year, and tended to stay at home more.

For some of the participants we can see a large number of very short trips by car, especially for two of the participants, who very rarely use any other mode of transport. Still, these short daily errands are hardly visible in Figs. 2 and 3.

\subsubsection{Knowledge of the cost of car ownership}

When recruiting participants in the street, the research assistants' scripts included the phrase that partaking in the study would let them know more about the car's real 


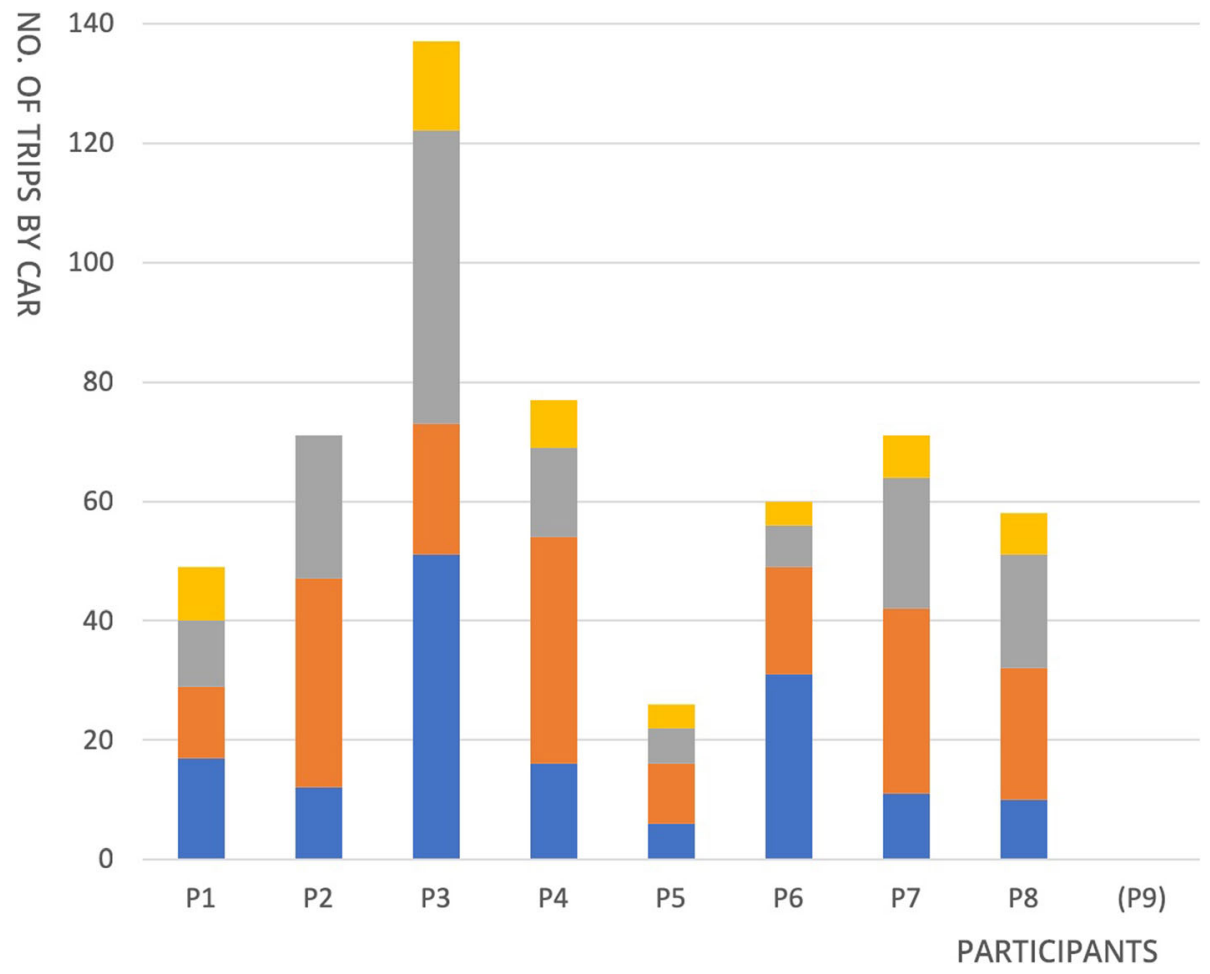

Fig. 4 Number of trips made by car in July

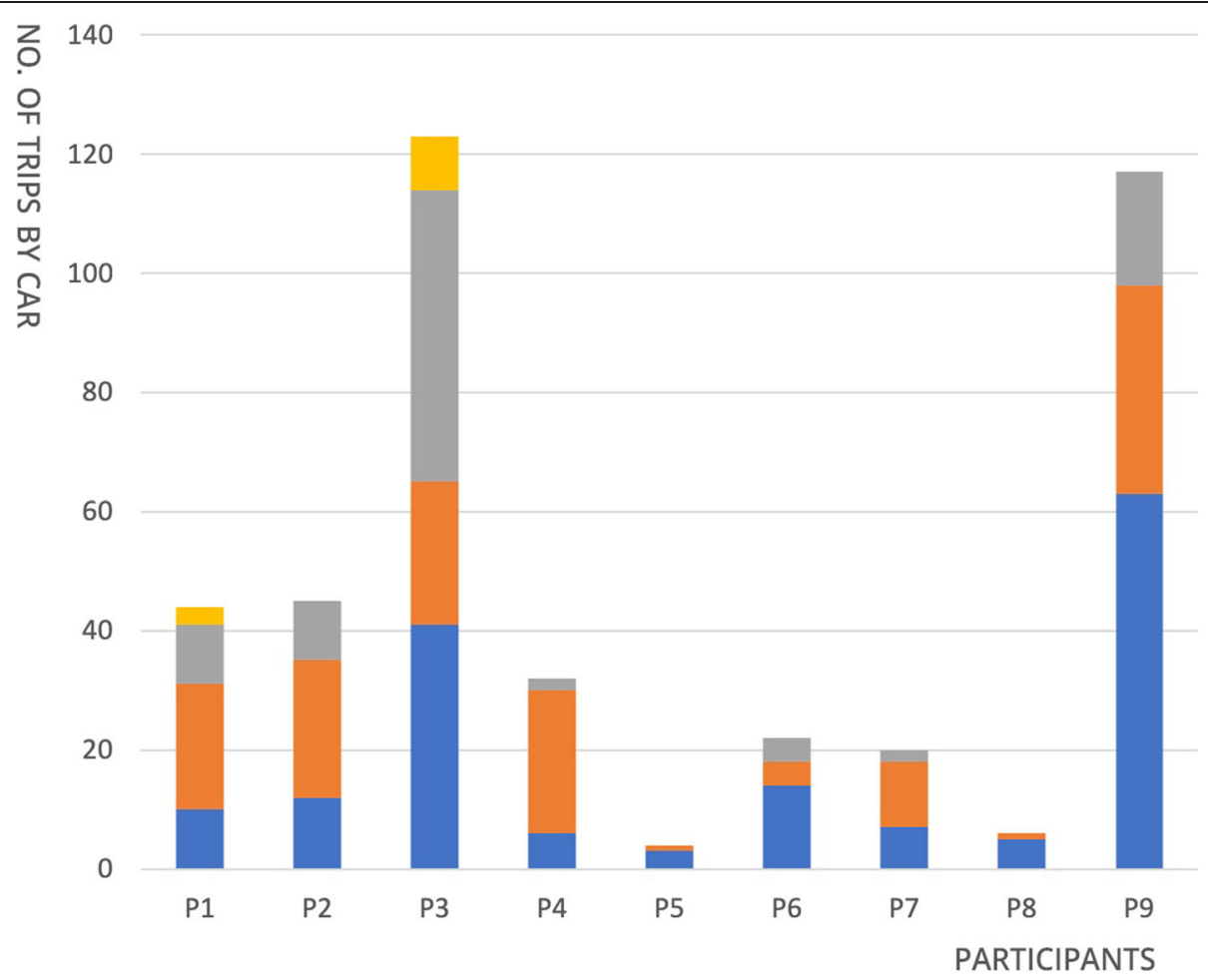

Fig. 5 Number of trips made by car in November 
costs, upon which very many answered similarly, with a laugh, saying "That's something you don't want to know".

Later, when asked about the costs of the car in the first interview, all the participants at first answered that they did not know. One participant jokingly said "Denial, denial!" as her first response. After that, she said that even though it was more than she liked to think about, her job paid a lot of the expenses and that she had finished paying off her loan for the car. Similar thoughts were commonly expressed among the participants.

During the first interview, the participants were asked to estimate the cost of their cars. All estimations except one were too low. In most cases the estimations were around two thirds of the real cost. During the interviews, many seemed unsure how to go about making the calculations. When guided however, they proved to have a reasonably good idea of many of the costs. Many of the participants could recall most of the costs normally paid by invoice. Other costs such as service and tires were almost never brought up by the participants themselves, but many had a fairly good idea when asked. Most importantly, only one participant independently considered depreciation, and nobody made a good estimation of this cost. It was clear that value loss was not something they would normally see as a cost, since the car was "already paid in full".

In a later interview, when asked about living expenses, none of the participants said that they made any sort of yearly or monthly budgets. In some cases they explained that this was because they knew that they could afford their current life styles. In one case a participant said that he never calculated the car's costs because then "I would have to realize that it probably costs more than my apartment".

\subsubsection{The car cost intervention - seeing the cost of each trip}

When confronted with a daily life-scenario that required comparing travel modes, the participants expressed that for occasional longer trips they normally only count fuel costs. As described in the background section, this is all in line with earlier research, but in this study the participants were also confronted with the total cost of driving, through the app, after every car trip. The reactions to this varied: Two participants expressed shock and dismay; two participants said the figures has had some effect, making them more conscious of the price of longer trips; and the other five said they were not affected. In the words of one of the participants: "There is some anguish to knowing those costs. I would think that a trip to [the girlfriend in another city] costs 400 SEK ( $40 €$, authors note), but then this [notification] comes up that the other costs are another 400 or 500 , meaning going there and back is some 2000 SEK. Thinking that
Table 4 Comparison of the approximate yearly cost of driving, using a car sharing service and the private car

\begin{tabular}{lll}
\hline & Car sharing service (SEK) & Private car (SEK) \\
\hline P7, P8 & 35,500 & 35,300 \\
P4 & 37,300 & 41,500 \\
P2 & 27,900 & 25,600 \\
P5, P6 & 33,500 & 38,100 \\
P1 & 35,440 & 29,800 \\
\hline
\end{tabular}

happens four times a month is outright scary! But then, you might not notice it that month".

\subsubsection{Results from a car sharing scenario}

Before the last interview, the detailed data of all trips made by car during the 6 months was used to calculate the cost of making the exact same trips using a car sharing service instead. The full yearly cost was then approximated, from the data and projections used earlier, as shown in Table 4. The calculation was made using the prices of the leading car sharing service in Sweden. In the calculations, the station-based car sharing solution was in a few cases complemented by taxi rides to avoid large stand-still costs. The calculations were purely hypothetical since there were generally no car sharing vehicles available in the suburbs where the participants lived. Two participants spontaneously suggested in early interviews that they might have used a car sharing service if they lived in an area where such services are in supply.

The total cost of the car sharing solution was in most cases close to the full cost of the private car. The comparison was made using the cheapest car model on offer, but this was still a new, medium-sized car (Volvo V40). If the participants' cars had been as new as the shared cars, the cost of the privately-owned cars would have been much higher.

The participants were then confronted with the hypothetical scenario of exchanging the private car with a car sharing solution, in a future where such cars were readily available in their area. For one participant that mostly takes the car daily to and from work, commuting was excluded, and the scenario included making these trips by public transport.

Although two participants were very interested in the figures and saw this as a possible future solution for them, the most common reaction was that much bigger savings were needed to let go of the freedom of having a car of one's own. A participant who considered the car sharing scenario to some depth remarked strongly that even though he now (by partaking in the study) knows that his own car costs 45,000 SEK/year, paying "that kind of amount" for a car sharing-service was simply "unthinkable". 
Only one participant commented on the fact that the car sharing vehicles were new and his was very old, but this fact didn't seem to make a difference. He just pointed out that the comparison "wasn't quite fair". Two participants expressed that it would be nice to be released from the risks and the hassles of car ownership.

When asked to visualize daily life using car sharing several participants described that it would require better planning and that this would lead to less driving, which supports the analysis presented by Cervero et al. [9].

\subsection{Public transport}

As 6 out of 9 participants used public transport for their daily commute, most reasons for using it related to these trips: saving time, being cheaper, and for those who frequently commuted by bicycle, as an alternative to bicycling when raining. Additionally, some mentioned getting some exercise walking to the nearest subway stop or getting personal time on-board for relaxing and listening to music. In the spare time 8 out of 9 participants mostly travelled by car, but some mentioned going to the city by public transport to avoid the parking hassle, and two participants said they used public transport when they could not drive, after having dinner and drinks with friends.

Specifically commuting-related reasons given for not going by public transport included views such as "it just feels heavy and cold to do early in the morning" and that it was heavy and uncomfortable to carry around work equipment. On a more general note, reasons for choosing car over public transport ranged from public transport trips taking too long time, a long walk to the closest train stop, and inconvenient transits. When the researchers made home-visits to participants that rarely used public transport themselves, these views became visible in several comments in the style of "Oh - did you walk here from the train? I could have picked you up!", or "Did you go by bus here? It is raining outside - isn't it?" This kind of comments were made by three participants that described always taking the car to the local grocery store and for picking up at the train station, even though these destinations were only around $1 \mathrm{~km}$ from home.

When asked about their views on public transport in Stockholm, many described that there is now more people in Stockholm and/or their living areas than there used to be, and that this has led to higher pressure on the public transport system and roads, which have not been sufficiently developed. However, these perceptions varied. One said public transport was, after all, rather reliable, while many expressed that the commuter trains were good when they worked, but had problems with reliability. The subway was described as more reliable, but often crowded during rush hours. Some thought that public transport was too expensive, both period tickets and single trips. Buses were seen as "without effect" and "almost adding to the congestion", and some participants said the buses they could use ran too seldom and/or were too crowded. Many participants had very little knowledge of bus-lines or time-tables except for the daily commute, and considered it an issue having to plan a trip to other destinations.

\subsubsection{The public transport intervention}

The participants rarely changed their routines in order to save money by travelling off-peak. In a few cases, they did so when it required only small changes to their normal routines, but expressed that the discount was not important. The travel logs indicated that some participants would often travel off-peak hours is one direction but not the other, and these participants confirmed that they could only travel off-peak in one direction. In those cases, the peak-hour fees would add up and result in the participant paying the normal monthly price. On the other hand, one of the participants who only used public transport occasionally, and normally during off-peak hours, used expensive single journey tickets and complained that these trips costed more than using her own car. In this case the rebate could make a difference.

\subsection{Bicycling}

\subsubsection{Reasons for bicycling}

Concerning bicycling, three of the participants said that they regularly used bicycling as a travel mode, and one used it when her car broke down. Their reasons for bicycling were often generally described as "positive feelings" and "liking it", but also saving time, getting some exercise, and bicycling being convenient. One of the participants expressed that "people take the bicycle because they cannot stand the congestion, whether by car or bus". This is in line with a study by de Kruijf et al. [11] finding that dissatisfaction with the car commute positively influenced modal shift to e-bike. Participants who were not regularly using bicycling as a mode of transport often explained this by a general feeling of it being complicated and/or uncomfortable. All participants also stated practical reasons for not bicycling, such as bad weather conditions, trouble changing and drying clothes at work, not wanting to arrive sweaty to the destination, having luggage, bicycle lanes in bad condition, or in one case feeling unsafe when bicycling after dark.

\subsubsection{The bicycling intervention}

None of the participants said that they were directly affected by being rewarded for bicycling, but many thought a reward could be motivating for others - or for themselves if the amount was higher. One participant thought the reward could motivate him to bicycle for a 
longer part of the year, which he later did. This thought was also supported by others, who added that a monetary reward could motivate bicyclists to get better equipment. Another participant described that getting the money "felt nice" because it signifies society is moving in the right direction: "...Those times when you have to go by car, there may be less congestion, and then you benefit from others getting a reward". This participant also stated that a monetary incentive could be motivating for him, but having a long commute he hit the ceiling too early in the month.

One participant mentioned that not having to pay for the public transport access card when bicycling was more important than the reward for bicycling. A married couple that was interviewed together, both thought that the economic factor was not very interesting in connection to bicycling, and that their respective preferences for bicycling or not had to do with completely different things. They believed a bicycling incentive should be there for public health purposes, but also suggested that a reward could be more interesting for someone in a more sensitive economic situation.

\section{Discussion}

\subsection{Low awareness of car costs may limit interest in alternatives}

The longer yearly vacation trips are mentioned by several of the participants as an important reason for owning a car, and also makes up for a major part of their driving. Even though this should mean that part of the fixed or semi-fixed car costs should reasonably be assigned to these trips, the participants only considered the fuel costs, accounting for only $20-40 \%$ of the car's full costs for the participants in this study. It is known that fixed costs are often not included in daily travel decisions (see e.g. $[29,33])$. The purchase of the car is a sort of "pre-paid package" that serves to lower the threshold for later use. It then follows that the full costs are never calculated, since this is not interesting until one questions the ownership. We also found that the participants could calculate the car costs fairly well when asked to. Choosing not to could therefore be interpreted as a subconscious strategy to allow oneself the freedom and convenience of the car.

In many cases the participants expressed that alternatives to the car, such as journeys by train, car sharing solutions and public transport were expensive, but when considering the cost of the car they only counted the fuel cost. When the full car cost was presented, the participants expressed that travelling by e.g. train did not seem as expensive anymore: "If one sees the cost directly in the app, one can feel it more. Like when we go to Eskilstuna, the train usually feels expensive..." (For reference, the distance between Eskilstuna and Stockholm is about $110 \mathrm{~km}$ ). In the same way, not being mindful of the full cost of the car, is likely to affect potential customers' views on MaaS pricing.

4.2 Car use habit limits propensity to look for alternatives Car-use habit has been described as a barrier to more sustainable practices, as information about other modes of travel is rarely considered [1]. A Norwegian survey separated transport users into two clusters: individuals who primarily use public and health-promoting transport (e.g. public transportation users, bicyclists) and car users, finding that car use habit was a negative predictor of public transportation use [46]. In the present study, most participants already used public transport for commuting, but for travel in the spare time they still displayed resistance to plan their travels, re-learn, or face inconvenience to manage without the car, even when presented with the economic reality of driving. This is in line with other qualitative studies, such as [22], finding that the preparation and planning needed for public transport is commonly perceived as requiring more cognitive effort than going by car.

The most habitual car owners in our study considered some bicycle or public transport trips, that others do on a daily basis, highly inconvenient or even impossible, grocery shopping being a common example. One participant explained that he couldn't take the train when visiting his car-free girlfriend in a small town $180 \mathrm{~km}$ from Stockholm. The reason was that her house was a two kilometre walk from the station. He also added "and then how would we be able to go grocery shopping?", seemingly without considering that his girlfriend manages to do her grocery shopping without a car when he is not there to visit.

\subsubsection{Shared mid-range mobility needs, or "middle-sized flows"}

Both quantitative and qualitative data were used to identify which types of mobility needs were most strongly connected to car driving in this study. The following section suggests separating these needs into three categories of trips that pose different challenges.

Large flows commuting to and from work. For our participants public transport is most commonly used for commuting, which is also the case for the Stockholm region as a whole [49]. For these large flows, public transport is generally effective. In the interviews, it was less common to express a need to commute by car; on the contrary, using car for these trips was described by many as impractical due to congestion and parking difficulties.

Small flows to unique/personal destinations such as the boat, the country house or visiting relatives out of 
reach of public transport. The resulting car journeys are often very long, and in those cases there could be opportunities for combined mobility, such as combining a train ride with car sharing services at the destination. However, since these unique and remote destinations often require long stand-still times for a car, they are hard to replace with today's car sharing services. While taking a taxi the last miles could sometimes be an alternative, it is not always easy to find taxis willing to drive those types of routes. Ridesharing would be difficult for the same reason. Furthermore, as previously discussed, the cost for making these journeys using the private car is commonly understood as only fuel costs, which makes alternatives seem expensive in comparison.

Apart from these two types of flows, several participants brought up common and recurring trips to shopping districts, recycling centres and recreational areas. These flows can be characterized as "middle-sized" mobility flows. These trips are often difficult or very time-consuming to do by public transport, but are still common destinations for many households in the same area. This means they could be an opportunity for digitalized mobility services such as public transport on demand or ride-sharing services.

The participants' car driving also differed over the year. It is nothing new that transport needs and wishes vary depending on the season and weather (see e.g. [37]). However, for the participants in this study these variations turned out to be very large. For a few of our participants, long car journeys during the vacation resulted in 50 times more driving in July than in November. A spontaneous weekend visit to a friend's country house may result in twice as much driving that month. This challenges the common idea about MaaS as something to buy with a subscription plan, as it is likely that a subscription that is suitable for November would not fulfil the needs in July. This could also be connected to previous research finding that the stated willingness to pay for MaaS is lower for those who use the car either very often or very rarely [28].

\subsection{Rewarding bicycling and off-peak travelling}

Those of our participants who used public transport for their daily commutes, did not make more than very small changes to save money from the rebate. However, for those who use public transport less frequently and mostly for off-peak travelling, the incentive could make public transport more competitive.

The bicycle reward also had only a small effect, although many of the participants liked the thought of it. Many believed it could motivate bicycling if the reward was larger, which is already the case in France and the Netherlands; de Kruijf et al .[11] report promising results from a study of such an incentives plan promoting e-cycling to work.

\subsection{New and traditional policy variants}

When talking about the barriers for sustainable transport options, the participants mentioned the reliability of trains and commuter trains, public transport routes and frequencies, safe and well-kept bicycle lanes, and cheaper public transport. While some of these issues might be partially addressed by smart mobility, some of them are of a larger political nature, such as infrastructure investments and upkeep.

Some attitudes and personal preferences varied between the participants, such as whether the time spent on public transport was perceived as useful, a calm moment for oneself or as uncomfortable, and whether cycling as transport was associated with refreshing exercise or discomfort and bad weather. Such preferences may be hard to address with solutions addressing practical issues, or monetary incentives, but the potential for positive experiences could be used to promote public transport, as suggested by Gardner and Abraham (2007).

The participants' views on car travel and what makes them choose it or not, also raises questions about how to treat traffic congestion. On the one hand, the participants expressed dissatisfaction with congestion levels and stressful traffic situations. On the other hand, these appeared to be the only major reasons not to take the car. This suggests that policies specifically aimed at reducing congestion may not be effective, as reductions in traffic may be quickly replaced by new cars. On the contrary, actions such as replacing car lanes with bicycle lanes, could increase congestion and the resulting emissions in the short run, but may encourage a shift to more sustainable travel modes.

\section{Conclusions}

Economic incentives for more sustainable travel modes have been tested and evaluated in many studies. In this study, we instead used qualitative methods to explore mobility practices, understandings and attitudes that may affect the effectiveness of such incentives. One insight is that many of our participants are not sensitive to costs because they know they can afford them, while the car-users who had a weaker economy felt they cannot manage without the car, and look upon higher taxes as "just a punishment". We know that economic incentives can reduce driving enough to reduce congestion, but they will likely not be enough to result in a broad transition away from the private car. As shown by Green and Stone (as cited in [19]), such levels of pricing would likely cause public opposition. Similarly, when introduced to the monetary interventions for bicycling and off-peak travel, most of our participants kept their normal routines. Some made changes when these did not diverge significantly from what they would normally have done. However, some also stated that they might 
have made changes if not for the limitations of the rewards, or if they were less well-off. Pricing and the design of such incentives is important, as shown by the example of several participants being able to travel public transport off-peak either to or from work but not both, thereby saving no money from the rebate.

Our living lab participants turned out to have several strategies to hide and repress the car's costs. Long journeys by car can be simultaneously understood as cheap for the car owner because they already own the car, and at the same time be a main reason for owning the car, since they make up a major part of yearly driving. The most common strategy seemed to be simply choosing not to know. Furthermore, the amount of car driving varies so much and so unpredictably, it will likely be hard to create MaaS subscription packages that help people hide the cost of using mobility services in the same way as car ownership. Supporting a more reality-based understanding of car costs may help make sustainable mobility solutions seem economically reasonable - not because people cannot afford the car, but by showing that alternatives that may appear to be expensive, such as car sharing or train rides, could actually save them money.

The convenience and freedom of the private car is hard to match by environmentally friendly modes of transport. There is a risk that the private car is simply replaced by new services that are still based on individual cars, while reducing the costs and hassles of car ownership.

We suggest more research to match the right services and policies to different categories of travel needs. For example, very long journeys may be partially replaced by train if new mobility services can cater for the needs at the destination, and the identified middle-sized flows may be an opportunity for public transport on demand, new ride sharing services, or home delivery for shopping. Commonly recurring car trips made during the spare time, and especially those made by people who normally commute by public transport, seem to hold opportunities for new service development. For new public transport routes and destinations, unwillingness to relearn and to plan the trips poses a challenge. Although travel planning support is a central concept in MaaS, mixing public transport and other modes will still require learning, timekeeping, and accepting transits.

Although digitalized mobility may help solve the flexibility problems of public transport, there is still room for improvement in the more traditional areas of capacity, punctuality and reliability. Likewise, urban management issues like the localisation of housing, services, and workplaces, will continue to play an important role in ensuring that bicycling and public transport are seen as real options.
These conclusions concern both the design of future mobility solutions and policy. We suggest that digitalized mobility services such as MaaS may have the potential to support a transition towards more sustainable transports in urban areas, if combined with policies that concern both the mobility services, and the physical infrastructure that supports them (e.g. public transport reliability). Traditional solutions regarding infrastructure and politics should not be forgotten in discussions about transitions to more sustainable mobility.

Our data suggests that what people value most about their cars - individually tailored departures to individual destinations, will be hard to replace by sustainable MaaS. MaaS is often referred to as "The Netflix of Transportation" $[2,16]$, but while the new digitalized media services offer an unlimited digital resource in a more accessible and flexible way than before, car rides rely on material and finite resources, and any improvement for the climate requires compromises such as shared and less individually tailored rides.

\section{Abbreviations}

MaaS: Mobility as a Service; PT: Public Transport; SL: Storstockholms Lokaltrafik, Stockholm Public Transport; TCO: Total Cost of Ownership

\section{Acknowledgements \\ This paper has been written in the context of the Mistra SAMS program, a collaboration between KTH Royal Institute of Technology, the Swedish National Road and Transport Research Institute VTI, K2 - the Swedish knowledge centre for public transport, University of Karlstad/SAMOT - the Service and Market Oriented Research Group, Lund University - IIIEE, Swedish Transport Administration, City of Stockholm, City of Malmö, Botkyrka municipality, Ericsson, FRAC/Hertz/Sunfleet, Scania, Open Lab, Samtrafiken, Savantic and Transformator Design. Members of the research group have participated in workshops regarding the Living Lab. Teo Enlund (KTH) has played an important part in the design and implementation of the study. The participants of the Living Lab have naturally played a major part in this study. We would like to thank all partners and other mentioned contributors.}

\section{Authors' contributions}

MS, TR and AK have all participated in designing the study, finding literature, formulating the interviews, and making the final analysis of the material. MS and TR performed the interviews with the participants and wrote the manuscript. MS performed the quantitative analysis, created the figures, and had the major responsibility for all the practical considerations regarding the monetary incentives and the travel logging application TravelVU. Sincerely, Martin Sjöman, Tina Ringensson and Anna Kramers. All authors read and approved the final manuscript

\section{Funding}

The main part of the funding has been provided by The Swedish Foundation for Strategic Environmental Research, Mistra. Funding has also been provided by ITRL Integrated Research Lab at KTH, the Swedish

Transport Administration, KTH Royal Institute of Technology and the Swedish National Road and Transport Research Institute VTI. The funding bodies have not been involved in the preparation of the manuscript. Open access funding provided by Royal Institute of Technology.

\section{Availability of data and materials}

The datasets generated and/or analysed during the current study are not publicly available due to protection of the privacy of the participants, but can be partially made available from the corresponding author on reasonable request. 


\section{Competing interests}

To the best of our knowledge, the named authors have no conflict of interest, financial or otherwise.

\section{Author details}

'Department of Product \& Service Design, KTH Royal Institute of Technology, Brinellvägen 83, SE-100 44 Stockholm, Sweden. ${ }^{2}$ Department of Strategic Sustainability Studies, KTH Royal Institute of Technology, Teknikringen 10B, SE-100 44 Stockholm, Sweden.

Received: 6 May 2019 Accepted: 11 December 2019 Published online: 23 January 2020

\section{References}

1. Aarts, H., Verplanken, B., \& Van Knippenberg, A. (1997). Habit and information use in travel mode choices. Acta Psychologica. https://doi.org/ 10.1016/s0001-6918(97)00008-5.

2. Abdullah, Z. (2017). "Netflix of transport" could offer unlimited use of public transport for flat fee, transport news \&amp; top stories - the straits times. Retrieved April 30, 2019, from straits time website: https://www.straitstimes. com/singapore/transport/netflix-of-transport-could-offer-unlimited-use-ofpublic-transport-for-flat-fee

3. Arnott, B., Rehackova, L., Errington, L., Sniehotta, F. F., Roberts, J., \& AraujoSoares, V. (2014). Efficacy of behavioural interventions for transport behaviour change: Systematic review, meta-analysis and intervention coding. International Journal of Behavioral Nutrition and Physical Activity. https://doi.org/10.1186/s12966-014-0133-9.

4. B-riders. (n.d.). B-Riders, fietsen naar het werk|B-Riders|Fietsen naar het werk. Retrieved April 30, 2019, from http://www.briders.nl/

5. Bamberg, S., Rölle, D., \& Weber, C. (2003). Does habitual car use not lead to more resistance to change of travel mode? Transportation. https://doi.org/ 10.1023/A:1021282523910.

6. Beirão, G., \& Sarsfield Cabral, J. A. (2007). Understanding attitudes towards public transport and private car: A qualitative study. Transport Policy, 14(6), 478-489. https://doi.org/10.1016/J.TRANPOL.2007.04.009.

7. Brög, W. (1982). Subjective perception of car costs. Transportation Research Record: Journal of the Transportation Research Board, 858, 43-38 Retrieved from http://onlinepubs.trb.org/Onlinepubs/trr/1982/858/858-010.pdf.

8. Burbridge, M. (2017). If Living Labs are the Answer - What's the Question? A Review of the Literature. Procedia Engineering. https://doi.org/10.1016/j. proeng.2017.04.335.

9. Cervero, R., Golub, A., \& Nee, B. (2007). City CarShare longer-term travel demand and car ownership impacts. Transportation Research Record. https:// doi.org/10.3141/1992-09.

10. Conway, M., Salon, D., King, D., Coll, M. H., Vandersmissen, M. H., Thériault, M., ... Bhat, C. R. (2017). Disruptive transportation: The adoption, utilization, and impacts of ride-hailing in the United States. Ssrn. https://doi.org/10. 1139/gen-44-3-401.

11. de Kruijf, J., Ettema, D., Kamphuis, C. B. M., \& Dijst, M. (2018). Evaluation of an incentive program to stimulate the shift from car commuting to ecycling in the Netherlands. Journal of Transport and Health. https://doi.org/ 10.1016/j.jth.2018.06.003.

12. Docherty, I., Marsden, G., \& Anable, J. (2018). The governance of smart mobility. Transportation Research Part A: Policy and Practice, 115, 114-125. https://doi.org/10.1016/J.TRA.2017.09.012.

13. Droit-finances. (n.d.). Indemnité kilométrique vélo - Mode d'emploi. Retrieved April 30, 2019, from https://droit-finances.commentcamarche.com/faq/4 8971-indemnite-kilometrique-velo-mode-d-emploi

14. Eriksson, J., Lindborg, E., Adell, E., Silvano, A. P., Nilsson, A., Henriksson, P., ... Dahlberg, L. (2018). New ways of collecting individual travel information evaluation of data collection and recruitment. https://doi.org/10.13140/RG.2.2.12050.91846

15. Eriksson, T., Betanzo, M., Johansson, M., \& Norheim, B. (2017). Hur får vi mer kollektivtrafik för pengarna?

16. Finnish Transport Agency. (2018). MaaS in Finland/FTA. Retrieved from http://www.nvfnorden.org/library/Files/Niklas Fieandt_Mobility as a Service (MaaS)_FTA_NVF_Digitalisering_20180207-08_final.pdf

17. Flügge, B. (2017). Introduction. In Smart mobility - connecting everyone (pp. 1-3). https://doi.org/10.1007/978-3-658-15622-0_1.

18. Gehrke, S., Felix, A., \& Reardon, T. (2019). Substitution of ride-hailing services for more sustainable travel options in the greater Boston region.
Transportation Research Record: Journal of the Transportation Research Board. https://doi.org/10.1177/0361198118821903.

19. Graham-Rowe, E., Skippon, S., Gardner, B., \& Abraham, C. (2011). Can we reduce car use and, if so, how? A review of available evidence. Transportation Research Part A: Policy and Practice. https://doi.org/10.1016/j.tra.2011.02.001.

20. Gärling, T., \& Axhausen, K. W. (2003). Introduction: Habitual travel choice. Transportation. https://doi.org/10.1023/A:1021230223001.

21. Gärling, T., \& Schuitema, G. (2007). Travel demand management targeting reduced private car use: Effectiveness, public acceptability and political feasibility. Journal of Social Issues. https://doi.org/10.1111/j.1540-4560.2007. 00500.x

22. Gardner, B., \& Abraham, C. (2007). What drives car use? A grounded theory analysis of commuters' reasons for driving. Transportation Research Part F: Traffic Psychology and Behaviour. https://doi.org/10.1016/j.trf.2006.09.004.

23. Gioia, D. A., Corley, K. G., \& Hamilton, A. L. (2013). Seeking Qualitative Rigor in Inductive Research: Notes on the Gioia Methodology. Organizational Research Methods. https://doi.org/10.1177/1094428112452151.

24. Hagman, J., Ritzén, S., \& Stier, J. J. (2017). The TCO paradox-A key problem in the diffusion of energy efficient vehicles? American Journal of Industrial and Business Management, 07(12), 1267-1284. https://doi.org/10.4236/ajibm. 2017.712090.

25. Hasselqvist, H., Hesselgren, M., \& Bogdan, C. (2016). Challenging the Car norm: Opportunities for ICT to support sustainable transportation practices. Proceedings of the $2016 \mathrm{CH}$ conference on human factors in computing systems - CHI'16. https://doi.org/10.1145/2858036.2858468.

26. Hagman, J., Ritzén, S., \& Stier, J. J. (2017). The TCO Paradox-A Key Problem in the Diffusion of Energy Efficient Vehicles? American Journal of Industrial and Business Management. https://doi.org/10.4236/ajibm.2017.712090.

27. Hesselgren, M., Hasselqvist, H., \& Sopjani, L. (2017). Design strategies for exploring and bridging: Intersections of everyday life and decision-making for sustainability. Conference proceedings of the design management academy: Research perspectives on creative intersections. https://doi.org/10. 21606/dma.2017.101

28. Ho, C. Q., Hensher, D. A., Mulley, C., \& Wong, Y. Z. (2018). Potential uptake and willingness-to-pay for Mobility as a Service (MaaS): A stated choice study. Transportation Research Part A: Policy and Practice. https://doi.org/10. 1016/j.tra.2018.08.025.

29. Huwer, U. (2004). Public transport and car-sharing - benefits and effectsof combined services. Transport Policy. https://doi.org/10.1016/j.tranpol.2003.08.002.

30. Jakobsson, C., Fujii, S., \& Gärling, T. (2002). Effects of economic disincentives on private car use. Transportation, 29(4), 349-370. https://doi.org/10.1023/A: 1016334411457

31. Jittrapirom, P., Caiati, V., Feneri, A.-M., Ebrahimigharehbaghi, S., González, M. J. A., \& Narayan, J. (2017). Mobility as a service: A critical review of definitions, assessments of schemes, and key challenges. Urban Planning, 2(2), 13. https://doi.org/10.17645/up.v2i2.931.

32. Kankainen, A., Vaajakallio, K., Kantola, V., \& Mattelmki, T. (2012). Storytelling group-a co-design method for service design. Behaviour and Information Technology. https://doi.org/10.1080/0144929X.2011.563794.

33. Katzev, R. (2003). Car sharing: A new approach to urban transportation problems. Analyses of Social Issues and Public Policy. https://doi.org/10.1111/j. 1530-2415.2003.00015.x.

34. Lättman, K., Friman, M., \& Olsson, L. E. (2016). Perceived accessibility of public transport as a potential indicator of social inclusion. Social Inclusion. https://doi.org/10.17645/si.v4i3.481

35. Lättman, K., Olsson, L. E., \& Friman, M. (2018). A new approach to accessibility - Examining perceived accessibility in contrast to objectively measured accessibility in daily travel. Research in Transportation Economics. https://doi.org/10.1016/j.retrec.2018.06.002.

36. Lidestam, H., Camén, C., \& Lidestam, B. (2018). Evaluation of cost drivers within public bus transports in Sweden. Research in Transportation Economics. https://doi.org/10.1016/j.retrec.2018.05.009.

37. Liu, C., Susilo, Y. O., \& Karlström, A. (2015). The influence of weather characteristics variability on individual's travel mode choice in different seasons and regions in Sweden. Transport Policy, 41, 147-158. https://doi. org/10.1016/J.TRANPOL.2015.01.001.

38. Mattelmäki, T. (2008). Probing for co-exploring. CoDesign. https://doi.org/10. 1080/15710880701875027.

39. Matyas, M., \& Kamargianni, M. (2019). Survey design for exploring demand for mobility as a service plans. Transportation, 46, 1525-1558. https://doi.org/ 10.1007/s11116-018-9938-8. 
40. Nalmpantis, D., Roukouni, A., Genitsaris, E., Stamelou, A., \& Naniopoulos, A. (2019). Evaluation of innovative ideas for public transport proposed by citizens using multi-criteria decision analysis (MCDA). European Transport Research Review, 11(1), 22. https://doi.org/10.1186/s12544-019-0356-6.

41. Noy, K., Givoni, M., Noy, K., \& Givoni, M. (2018). Is 'smart mobility' sustainable? Examining the views and beliefs of transport's technological entrepreneurs. Sustainability, 10(2), 422. https://doi.org/10.3390/su10020422.

42. Ouellette, J. A., \& Wood, W. (1998). Habit and intention in everyday life: The multiple processes by which past behavior predicts future behavior. Psychological Bulletin. https://doi.org/10.1037/0033-2909.124.1.54

43. Pangbourne, K., Stead, D., Mladenović, M., \& Milakis, D. (2018). The case of mobility as a service: A critical reflection on challenges for urban transport and mobility governance. In Governance of the smart mobility transition. https://doi.org/10.1108/978-1-78754-317-120181003.

44. Parkin, J., Wardman, M., \& Page, M. (2007). Estimation of the determinants of bicycle mode share for the journey to work using census data. Transportation, 35(1), 93-109. https://doi.org/10.1007/s11116-007-9137-5.

45. Sælensminde, K. (2004). Cost-benefit analyses of walking and cycling track networks taking into account insecurity, health effects and external costs of motorized traffic. Transportation Research Part A: Policy and Practice, 38(8), 593-606. https://doi.org/10.1016/J.TRA.2004.04.003.

46. Şimşekoğlu, Ö., Nordfjærn, T., \& Rundmo, T. (2015). The role of attitudes, transport priorities, and car use habit for travel mode use and intentions to use public transportation in an urban Norwegian public. Transport Policy, 42, 113-120. https://doi.org/10.1016/J.TRANPOL.2015.05.019.

47. Sopjani, L., Stier, J. J., Ritzén, S., Hesselgren, M., \& Georén, P. (2019). Involving users and user roles in the transition to sustainable mobility systems: The case of light electric vehicle sharing in Sweden. Transportation Research Part D: Transport and Environment, 71(December 2018), 207-221. https://doi.org/ 10.1016/j.trd.2018.12.011.

48. Stockholm Public Transport (SL). (2015). Fakta om SL och länet 2014. Retrieved from http://www.sll.se/Global/Nerksamhet/Kollektivtrafik/Fakta om SL och länet/Fakta om SL och länet 2014.pdf

49. Stockholm Public transport administration. (2016). Resvanor i Stockholms län 2015. Retrieved from https://www.sll.se/globalassets/2.-kollektivtrafik/ kollektivtrafiken-vaxer-med-stockholm/su/resvaneundersokningen/resvanor-istockholms-lan-2015-version-20160817.pdf

50. Tyrinopoulos, Y., \& Antoniou, C. (2013). Factors affecting modal choice in urban mobility. European Transport Research Review, 5(1), 27-39. https://doi. org/10.1007/s12544-012-0088-3.

51. Wardman, M., Tight, M., \& Page, M. (2007). Factors influencing the propensity to cycle to work. Transportation Research Part A: Policy and Practice. https://doi.org/10.1016/j.tra.2006.09.011.

52. Xing, Y., Handy, S. L., \& Mokhtarian, P. L. (2010). Factors associated with proportions and miles of bicycling for transportation and recreation in six small US cities. Transportation Research Part D: Transport and Environment, 15(2), 73-81. https://doi.org/10.1016/J.TRD.2009.09.004.

53. Yang, N., \& Long Lim, Y. (2018). Temporary incentives change daily routines: Evidence from a field experiment on Singapore's subways. Management Science, 64(7), 3365-3379. https://doi.org/10.1287/mnsc.2017.2731.

\section{Publisher's Note}

Springer Nature remains neutral with regard to jurisdictional claims in published maps and institutional affiliations.

\section{Submit your manuscript to a SpringerOpen ${ }^{\circ}$ journal and benefit from:}

- Convenient online submission

- Rigorous peer review

- Open access: articles freely available online

- High visibility within the field

- Retaining the copyright to your article

Submit your next manuscript at $\boldsymbol{\nabla}$ springeropen.com 